\title{
Primary brachial plexus tumors: imaging, surgical, and pathological findings in 25 patients
}

\author{
Devin K. Binder, M.D., Ph.D., Justin S. SMith, M.D., Ph.D., \\ AND Nicholas M. BARBARO, M.D. \\ Department of Neurological Surgery, University of California, San Francisco, California
}

\begin{abstract}
Object. The authors report on the treatment of primary brachial plexus tumors in 25 patients at the University of California, San Francisco. They compare their findings with those obtained in similar series.

Methods. The authors reviewed the electronic and medical records, radiological images, operative reports, and pathological findings in 25 consecutive cases of primary brachial plexus tumors. Cases of metastatic lesions or adjacent neoplasms extending into and involving the brachial plexus were excluded.

At presentation patients ranged in age from 19 to 71 years (mean $47 \pm 15$ years), and neurofibromatosis was present in eight patients (32\%). Presenting signs and symptoms included palpable mass (60\%), numbness/paresthesias $(44 \%)$, radiating pain (44\%), local pain $(16 \%)$, and weakness (12\%). Duration of symptoms ranged from 2 months to 10 years. Neuroimaging revealed lesions ranging widely in size (volume $\sim 1$ to $>100 \mathrm{ml}$ ). Pathological diagnoses included schwannoma (15 [60\%]), neurofibroma (five [20\%]), malignant peripheral nerve sheath tumor (four [16\%]), and desmoid tumor (one [4\%]).

Conclusions. Primary tumors arising in the brachial plexus are rare. Careful workup, surgical technique, and attention to pathological diagnosis optimize management.
\end{abstract}

\section{KEY WoRDS • brachial plexus • schwannoma • neurofibroma • sarcoma • peripheral nerve tumor}

Although many series of peripheral nerve tumors have been reported, $1,7-9,12,14,21,28,29,31,34,35$ few have been specifically and separately conducted to examine primary tumors of the brachial plexus. The authors of some larger series have reported peripheral nerve tumors in the head and neck but did not classify primary brachial plexus tumors separately. In a series involving 303 peripheral nerve tumors at Memorial Sloan-Kettering Cancer Center, 136 $(45 \%)$ were located in the head and neck region. ${ }^{10}$ In 50 cases treated at the University of Illinois, 15 (30\%) were located in the head and neck region. ${ }^{9}$ In an extensive review of 120 patients harboring MPNSTs treated at the Mayo Clinic during a 71-year period, Ducatman, et al. ${ }^{14}$ indicated that $23(19 \%)$ were located in the head and neck. Artico, et al., ${ }^{1}$ reported 119 peripheral nerve sheath tumors, including 11 in the brachial plexus region.

The largest recent series of brachial plexus tumors was treated at LSUHSC. . $^{11,20,25,29}$ In addition to providing a comprehensive review of the literature regarding brachial plexus tumors, Lusk, et al. ${ }^{29}$ discussed the management of 57 brachial plexus tumors in 56 patients between

\footnotetext{
Abbreviations used in this paper: EBRT = external-beam radiotherapy; LSUHSC = Louisiana State University Health Sciences Center; MPNST = malignant peripheral nerve sheath tumor; MR = magnetic resonance; $\mathrm{NF}=$ neurofibromatosis; $\mathrm{SD}=$ standard deviation; UCSF = University of California at San Francisco.
}

1968 and 1985. Of the 40 neural sheath-associated tumors, there were 26 neurofibromas, eight schwannomas, five MPNSTs, and one meningioma. The remaining $17 \mathrm{tu}-$ mors included benign nonneural tumors (for example, desmoid and lipoma) and malignant nonneural tumors (breast cancer and lung cancer infiltration of the plexus). In 2001, Ganju, et al. ${ }^{20}$ reported on 111 brachial plexus tumors in 107 patients seen at LSUHSC between 1986 and 1998. In this later group, there were 36 schwannomas, 33 neurofibromas, 12 MPNSTs, 13 benign nonneural tumors, and 17 malignant nonneural tumors.

In this study, we reviewed the cases of primary nerve tumors arising in the brachial plexus at our institution during a 10-year period. We specifically excluded cases involving metastatic disease from our analysis in an attempt to examine the characteristics of primary brachial plexus tumors. Clinical presentation, neuroimaging, surgical, and pathological findings were reviewed.

\section{CLINICAL MATERIAL AND METHODS}

\section{Patient Population}

This study was conducted following an approved protocol from the Committee on Human Research at UCSF (approval no. H2338-24681-01). All patients presenting to UCSF with primary brachial plexus tumors between No- 
vember 1992 and April 2003 were included in this study. There were 25 patients (18 women and seven men) who ranged in age from 19 to 71 years $(47 \pm 15$ years [mean $\pm \mathrm{SD}]$ ).

\section{Clinical, Neuroimaging, and Pathological Data}

Available chart and electronic medical records were reviewed. Presenting signs and symptoms and relevant medical history were identified, with particular attention given to a history of NF, prior radiotherapy, or other tumors. Magnetic resonance imaging studies and reports were also reviewed to establish tumor size/volume, characteristics, and location.

\section{Surgical Approach}

Patients were positioned supine and general anesthesia was administered. In most cases, an anterior supraclavicular approach was used. Briefly, a curvilinear incision was made above the clavicle to conform to a skin crease. Sharp dissection was brought down through the skin and the platysma muscle. Depending on the site of the lesion (upper, middle, or lower trunk), the sternocleidomastoid muscle was detached from the clavicular head to facilitate exposure. In some cases, such as with inferior trunk lesions, infraclavicular exposure was required. The supraclavicular fat was dissected, and the omohyoid muscle was retracted. Careful attention was given to isolation and identification of all possible elements of the brachial plexus. Intraoperative stimulation and electromyography were conducted to define plexal anatomy and motor innervation. This allowed identification and sacrifice of nonfunctioning fascicles entering tumors. Once the tumor was identified grossly, the surgical microscope was brought into the field and used to assist in microdissection of the tumor and tumor capsule margins. Successive steps included dissection of adjacent plexus or nonneural elements away from the tumor, identification and opening of the tumor capsule with concurrent intraoperative stimulation, and dissection of tumor away from adjacent nerve fascicles. In cases in which potentially significant motor impairment could result from sacrifice of nerve fascicles by gross-total removal of the tumor, a thin rind of tumor was left to preserve nerve continuity. Thus, the extent of tumor removal varied from extracapsular excision (grosstotal resection), subcapsular gross-total resection, and subtotal resection.

\section{Pathological Examination}

In all cases, frozen-section specimens were sent for pathological evaluation. For the purposes of this report, we considered only the final pathological diagnosis. Detailed reports were examined to extract information about tumor size (in $\mathrm{cm}$ ) and final pathological diagnosis.

\section{RESULTS}

\section{Characteristics and Clinical Presentation}

In our review we identified 25 patients with primary brachial plexus tumors. Neurofibromatosis was present in eight patients $(32 \%)$. There was a trend toward younger age in those with NF $(40 \pm 19$ years [mean \pm SD] $)$ compared with the patients without this diagnosis $(51 \pm 12$ years) $(\mathrm{p}=0.08)$.

\section{K. Binder, J. S. Smith, and N. M. Barbaro}

Demographic and clinical characteristics are summarized in Table 1. Presenting signs and symptoms included the following: mass (60\%), paresthesias/numbness $(44 \%)$, radiating pain $(44 \%)$, local pain $(16 \%)$, and weakness $(12 \%)$. The duration of symptoms ranged from 2 months to 10 years prior to treatment. In one case the lesion was discovered incidentally. Two patients $(8 \%)$ had previously undergone EBRT, one for breast cancer and one for lymphoma.

\section{Tumor Characteristics}

The 25 tumors comprised a heterogeneous group of lesions, both in size and location (Table 2). The smallestvolume lesions were approximately $1 \mathrm{ml}$ in volume and the largest were in excess of $100 \mathrm{ml}$. Tumors were found along the plexus at all points from the nerve roots and neural foramina through the distal plexus and proximal exiting nerves.

\section{Intraoperative and Pathological Findings}

Of 25 tumors, there were 15 schwannomas (60\%) (Fig. 1A), five neurofibromas (20\%) (Fig. 1B), four MPNSTs (16\%), (Fig. 1C), and one desmoid tumor (4\%) (Fig. 1D). All five neurofibromas and one of four MPNSTs were associated with a history of NF. Gross-total resection was achieved in all cases with schwannomas and in one of the five with neurofibromas. One intraoperative complication occurred: avulsion of an artery supplying the tumor from the right subclavian artery during tumor mobilization, but was successfully repaired without clinical sequelae.

\section{DISCUSSION}

\section{Epidemiology and Presenting Symptoms}

The mean age at diagnosis (47 years) in our series was higher than that in most series. The authors of a Mayo Clinic series of 120 MPNSTs reported a mean patient age of 35 years. ${ }^{14}$ In the most recent LSUHSC series, investigators reported a mean age of 25 years in cases involving neurofibromas associated with NF, 42 years in those with non-NF-associated neurofibromas, 42 years in those with schwannomas, and 44 years in cases involving MPNSTs. ${ }^{20}$ Interestingly, we observed a sex predilection, with 18 women and seven men in our series, which has been noted in some but not all other series. Of 120 patients in the Mayo series involving patients with MPNSTs, 52 were men and 68 were women. ${ }^{14}$ In the Memorial SloanKettering series of 303 patients, $57 \%$ were women and $43 \%$ were men..$^{10}$ In the recent LSUHSC series of 107 patients, however, $49 \%$ were men and $51 \%$ were women. ${ }^{20}$

Patients with peripheral nerve tumors usually present with pain and paresthesias or with a palpable mass. ${ }^{11,20,25,29}$ In our series, the most common presenting symptoms were palpable mass, numbness/paresthesias, pain, and weakness, symptomatology in agreement with that in the LSUHSC series. ${ }^{20,29}$ Most often, early in the course, minimal neurological deficit will be present or there will be none at all. Manipulation of the mass can produce paresthesias or "shocks" in the distribution of the affected nerve, and this can be an important aid to diagnosis. Sideto-side greater than longitudinal mobility of the mass from the nerve is more common in cases of benign lesions, 
TABLE 1

Demographic and clinical data at presentation in 25 patients with brachial plexus tumors

\begin{tabular}{|c|c|c|c|}
\hline Case No. & Age (yrs), Sex & NF & Clinical Signs and Symptoms \\
\hline 1 & $53, \mathrm{M}$ & yes & It supraclavicular mass for $10 \mathrm{yrs}$, recently enlarging; progressive local pain w/ radiation down forearm to hand for $1 \mathrm{yr}$ \\
\hline 2 & $32, \mathrm{~F}$ & no & $\begin{array}{l}\text { painless lt supraclavicular mass for } 2 \text { mos; manipulation of mass causes paresthesias/pain along ventral arm \& forearm \& } \\
\text { third digit; decreased pinprick sensation in medial palm and ventral forearm }\end{array}$ \\
\hline 3 & $21, \mathrm{~F}$ & yes & painless lt supraclavicular mass; slight wasting of lt biceps; Grade 4+/5 lt biceps weakness \\
\hline 4 & $71, \mathrm{~F}$ & yes & $\begin{array}{l}2 \text {-yr history of rt supraclavicular nodule; resection } 6 \text { mos prior to current op; persistent rt posterior neck \& interscapular } \\
\text { pain }\end{array}$ \\
\hline 5 & $69, \mathrm{~F}$ & no & 1-yr history of lt neck mass; 1-mo history of lt hand paresthesias \\
\hline 6 & 49, M & no & 1 -yr history of painless enlarging rt supraclavicular mass \\
\hline 7 & $71, \mathrm{~F}$ & no & lt lat forearm-to-wrist paresthesias \\
\hline 8 & $50, \mathrm{M}$ & no & painless enlarging rt supraclavicular mass \\
\hline 9 & $28, \mathrm{~F}$ & yes & 2 -yr history of $\mathrm{rt}$ arm pain radiating to 4 th $\& 5$ th fingers \\
\hline 10 & $52, \mathrm{~F}$ & no & history of metastatic breast cancer w/ prior EBRT presenting w/ enlarging lt supraclavicular mass \\
\hline 11 & $28, \mathrm{~F}$ & yes & progressive $1 \mathrm{t}$ arm pain \\
\hline 12 & $43, \mathrm{~F}$ & no & 10-yr history of pain \& numbness in lt hand; decreased grip strength \\
\hline 13 & $40, \mathrm{M}$ & no & 5-yr history of enlarging 1 t axillary mass; severe pain \& paresthesias in 1 t C-7 distribution \\
\hline 14 & 47, M & no & lymphoma with prior EBRT 20 yrs ago; 1-yr history of increasing rt arm pain \\
\hline 15 & $42, \mathrm{~F}$ & yes & lt arm \& shoulder pain, numbness, paresthesias \\
\hline 16 & $19, \mathrm{M}$ & yes & enlarging $1 \mathrm{t}$ supraclavicular mass \& $1 \mathrm{t}$ arm paresthesias \\
\hline 17 & $52, \mathrm{~F}$ & no & $\begin{array}{l}\text { 5-yr history of enlarging lt supraclavicular mass w/ paresthesias in lt 2nd \& 3rd fingers w/ mild lt upper-extremity } \\
\text { weakness }\end{array}$ \\
\hline 18 & $30, \mathrm{~F}$ & no & $1-y r$ history of $1 t$ shoulder \& deltoid pain \\
\hline 19 & $53, \mathrm{M}$ & no & 3-yr history of intermittent severe $\mathrm{rt}$ neck pain radiating to $\mathrm{rt}$ thumb \& index finger \\
\hline 20 & $49, \mathrm{~F}$ & no & $\begin{array}{l}\text { history of breast cancer w/ lt modified radical mastectomy w/out EBRT; 4-yr history of burning paresthesias along ulnar } \\
\text { aspect of lt hand; symptoms induced by pressure on lt clavicle }\end{array}$ \\
\hline 21 & $47, \mathrm{~F}$ & yes & rt axillary mass associated $\mathrm{w} /$ local pain \\
\hline 22 & $68, \mathrm{~F}$ & no & 4-yr history of slowly enlarging lt supraclavicular mass; numbness of 1 t thumb \& index finger \\
\hline 23 & $52, \mathrm{~F}$ & no & 10-yr history of enlarging $\mathrm{rt}$ neck mass; pain radiating down $\mathrm{rt}$ arm \\
\hline 24 & $40, \mathrm{M}$ & no & $\begin{array}{l}\text { 4-yr history of rt index finger paresthesias; 1-yr history of rt hand cramping; symptoms triggered by shoulder movement } \\
\text { or suprascapular pressure }\end{array}$ \\
\hline 25 & $66, \mathrm{~F}$ & no & incidental lt brachial plexus mass identified during staging workup for breast cancer \\
\hline
\end{tabular}

whereas malignancy is associated with firmness and immobility. ${ }^{20,26}$

\section{Radiological and Neuroimaging Findings}

In cases of brachial plexus lesions, MR imaging is the study of choice to delineate the margins of the tumor from surrounding tissues with greatest contrast. ${ }^{22}$ Importantly, however, MR imaging is currently unable to differentiate between schwannoma and neurofibroma. ${ }^{5}$ Other imaging modalities may be useful in selected cases. Plain radiography can demonstrate apical pulmonary lesions potentially involving the brachial plexus. Computerized tomography scanning is optimal at revealing osseous erosion around the spine or changes in neural foramina. A newer modality, MR neurography, has the potential to demonstrate the entire course of visualized peripheral nerves. ${ }^{17,18}$

\section{Pathological Features}

It has been well established that the most common primary nerve tumors arise from the neural sheath. These include benign nerve sheath tumors, schwannomas, and neurofibromas. ${ }^{4,15}$ In our series, schwannomas and neurofibromas together accounted for $20(80 \%)$ of 25 tumors.

Other benign tumors can arise from nerves but not nerve sheaths, including desmoids, ganglions, cysts, epidermoids, and lipomas. ${ }^{20,29}$ Of the 20 nonneural brachial plexus lesions reported in the two LSUHSC series, ${ }^{20,29}$ there were seven desmoids, three lipomas, three myositis ossificans, and one each of localized hypertrophic neu- ropathy, myoblastoma, cavernous angioma, hemangioma, lymphangioma, ganglioneuroma, and brachial cleft cyst. In our series, we observed a single desmoid tumor (Table 2, Case 8, Fig. 1D). Desmoid tumors are composed of infiltrative mesenchymal tissue, can encase and invade nerves and blood vessels, and are thus difficult to resect completely. 6,26 Another nonneoplastic lesion that may rarely involve the brachial plexus is the neuromuscular hamartoma ("triton") tumor. ${ }^{2}$

Nonneoplastic lesions, especially hypertrophic neuropathy, may simulate neoplasms of the brachial plexus. Most commonly, interstitial hypertrophic neuropathy manifests as a sensorimotor polyneuropathy, and symptoms are usually bilateral with other associated neurological findings; however, several cases have been described in which patients presented with focal lesions ${ }^{20,23,32,33}$ including tumorlike infiltration of the brachial plexus. ${ }^{33}$ This condition may lead to thickening of peripheral nerves; evaluation of biopsy specimens demonstrates onion-bulb formation..$^{33}$

Also termed neurogenic sarcoma and neurofibrosarcoma, MPNSTs are thought to be of neural origin., ${ }^{45}$ Other nonneural malignant tumors, such as soft-tissue sarcomas, can involve nerves by direct extension or metastasis. Although a small number of cases of MPNSTs have been reported in patients without $\mathrm{NF}^{7,31}$ it has long been recognized that NF (especially NF Type 1, von Recklinghausen disease) is associated with a high incidence of MPNST. In 1931, Hosoi ${ }^{24}$ calculated that MPNST develops in approximately $13 \%$ of patients with von Recklinghausen disease. 
TABLE 2

Summary of imaging, surgical, \& pathological data*

\begin{tabular}{|c|c|c|c|c|}
\hline Case No. & Imaging Characteristics & Surgical Details & $\begin{array}{l}\text { Extent of } \\
\text { Resection }\end{array}$ & $\begin{array}{c}\text { Pathological } \\
\text { Diagnosis }\end{array}$ \\
\hline 1 & $\begin{array}{l}4 \times 3 \times 3-\mathrm{cm} \text { lt supraclavicular } \\
\text { tumor w/ well-circumscribed border }\end{array}$ & subcapsular resection & GTR & schwannoma \\
\hline 2 & $\begin{array}{l}2.5 \times 2.5 \times 3-\mathrm{cm} \text { tumor at inferior } \\
\text { border of lt anterior } \& \text { middle } \\
\text { scalene muscles }\end{array}$ & tumor involved middle trunk of brachial plexus & GTR & schwannoma \\
\hline 3 & $\begin{array}{l}\text { large tumor widening lt } \mathrm{C} 4-5 \\
\text { neural foramen }\end{array}$ & $\begin{array}{l}\text { lt C-5 schwannoma \& multiple other plexus lesions; motor roots } \\
\text { traversed lesion }\end{array}$ & STR & neurofibroma \\
\hline 4 & $1.5 \times 1.2 \times 0.7-\mathrm{cm} \mathrm{rt} \mathrm{BPT}$ & distal portion of upper trunk; motor roots traversed tumor & STR & neurofibroma \\
\hline 5 & $4.8 \times 3.5 \times 2.2-\mathrm{cm}$ lt BPT & tumor extended from C-5 foramen to upper trunk & GTR & schwannoma \\
\hline 6 & $5.4 \times 4.5 \times 3-\mathrm{cm} \mathrm{rt} \mathrm{BPT}$ & tumor over anterior scalene group; subclavian artery laceration repaired & GTR & schwannoma \\
\hline 7 & $3.9 \times 1.8 \times 1.1-\mathrm{cm}$ lt BPT & tumor involved upper trunk \& C-5 \& C-6 nerve roots & GTR & schwannoma \\
\hline 8 & $\begin{array}{l}4.8 \times 6.1 \times 6.6-\mathrm{cm} \text { rt supra- } \\
\& \text { infraclavicular BPT }\end{array}$ & clavicle head resection; multiple plexus branches traversed tumor & STR & desmoid \\
\hline 9 & $\begin{array}{l}5 \times 6 \times 4.8-\mathrm{cm} \text { tumor in } \\
\text { rt distal axilla }\end{array}$ & tumor attached to median nerve fascicles & GTR & neurofibroma \\
\hline 10 & $1.9 \times 1.6 \times 6-\mathrm{cm} \mathrm{lt} \mathrm{BPT}$ & $\begin{array}{l}\text { tumor arose from lower trunk w/ extensive plexus involvement } \\
\& \text { extended under clavicle }\end{array}$ & STR & MPNST \\
\hline 11 & $4.2 \times 3.7 \times 2.1-\mathrm{cm}$ lt BPT & subcapsular resection & STR & neurofibroma \\
\hline 12 & $4 \times 3 \times 2-\mathrm{cm}$ lt BPT & tumor arose from proximal ulnar nerve; subcapsular resection & GTR & schwannoma \\
\hline 13 & $2 \times 2 \times 2-\mathrm{cm}$ lt BPT & tumor attached to median nerve & GTR & schwannoma \\
\hline 14 & $\begin{array}{l}3.9 \times 2.4 \times 1.9-\mathrm{cm} \text { tumor } \\
\text { enlarged } \mathrm{rt} \mathrm{C} 7-\mathrm{T} 1 \text { neural foramen; } \\
\text { involved } \mathrm{rt} \mathrm{C}-8 \& \mathrm{~T}-1 \text { nerve roots }\end{array}$ & tumor involved C-8, T-1, \& lower trunk & STR & MPNST \\
\hline 15 & $\begin{array}{l}5.2 \times 3.2 \times 2.9-\mathrm{cm} \text { tumor at } \\
\text { lt C5-6 neural foramen }\end{array}$ & tumor involved C-5 root \& upper trunk & STR & MPNST \\
\hline 16 & $2.3 \times 0.9 \times 0.6-\mathrm{cm}$ lt BPT & tumor involved upper $\&$ middle trunks w/ multiple traversing motor fibers & STR & neurofibroma \\
\hline 17 & $4 \times 3.5 \times 1-\mathrm{cm} \mathrm{lt} \mathrm{BPT}$ & tumor involved upper trunk & GTR & schwannoma \\
\hline 18 & $1.2 \times 1.1 \times 1-\mathrm{cm} \mathrm{lt} \mathrm{BPT}$ & tumor involved lower trunk & GTR & schwannoma \\
\hline 19 & $2.5 \times 2 \times 1-\mathrm{cm} \mathrm{rt} \mathrm{BPT}$ & tumor arose from C-6 root & GTR & schwannoma \\
\hline 20 & $3 \times 2.5 \times 4-\mathrm{cm} \mathrm{lt} \mathrm{BPT}$ & tumor involved middle scalene; poorly encapsulated & STR & MPNST \\
\hline 21 & not available & tumor involved proximal rt ulnar nerve & GTR & schwannoma \\
\hline 22 & $5.4 \times 3.3 \times 2.7-\mathrm{cm}$ lt BPT & tumor involved lt upper trunk & GTR & schwannoma \\
\hline 23 & $5.2 \times 4.3 \times 5-\mathrm{cm} \mathrm{rt} \mathrm{BPT}$ & tumor involved rt upper trunk & GTR & schwannoma \\
\hline 24 & $3 \times 2.7 \times 1.7-\mathrm{cm} \mathrm{rt} \mathrm{BPT}$ & tumor involved rt lower trunk; required subclavicular exposure & GTR & schwannoma \\
\hline 25 & $1.2 \times 1.2 \times 1-\mathrm{cm} \mathrm{lt} \mathrm{BPT}$ & tumor involved lt upper trunk & GTR & schwannoma \\
\hline
\end{tabular}

$* \mathrm{BPT}=$ brachial plexus tumor; GTR $=$ gross-total resection; $\mathrm{STR}=$ subtotal resection.

Based on longer-term observation of a large series of patients, Brasfield and Das Gupta ${ }^{3}$ reported an overall incidence of $29 \%$. In our series, one of four patients with MPNSTs also had NF.

Interestingly, three of our four patients with MPNSTs did not have NF; two of these patients had previously undergone radiotherapy, one for breast carcinoma and one for lymphoma. These lesions are probably best considered as postirradiation sarcomas. Indeed, the Mayo Clinic series of 120 consecutive MPNSTs included 13 cases of postirradiation sarcomas. ${ }^{14}$ In that study, the latency period (duration between radiotherapy and tumor diagnosis) was 17 years (range 5-29 years). Other authors have also reported the appearance of MPNSTs at sites previously irradiated. ${ }^{13,16,19,30}$ In addition, the fact that radiation can induce brachial plexopathy can potentially create a diagnostic dilemma. ${ }^{27}$ Other than two patients having undergone radiotherapy, there was nothing in the clinical presentation of these cases to aid in the prediction that a malignant tumor was present. In cases of NF, the presence of an enlarging mass or new pain may indicate the need for aggressive resection; however, several patients in this series presented with pain and/or an enlarging mass and harbored benign lesions. Thus, the presence of a new mass in the supraclavicular region should lead to recommendation for surgical exploration.

\section{Procedure-Related Complications}

Serious complications due to brachial plexus operations are infrequent. The primary risk is of neurological dysfunction caused by interruption of critical motor branches to arm and hand. In addition, however, plexus tumors can adhere to major vessels. In our series, there was one complication of vascular injury to the right subclavian artery during tumor mobilization (Case 6). Similarly, Ganju, et al., ${ }^{20}$ reported two cases of vascular injury during tumor removal.

\section{CONCLUSIONS}

We have reported the findings in 25 consecutive cases involving primary brachial plexus tumors (15 schwannomas, five neurofibromas, four MPNSTs, and one desmoid) seen at UCSF over a 10-year period. Clinical presentation most commonly included palpable mass, pain, numbness, or paresthesias. Gross-total removal was possible in all cases of schwannomas, whereas the other lesions 

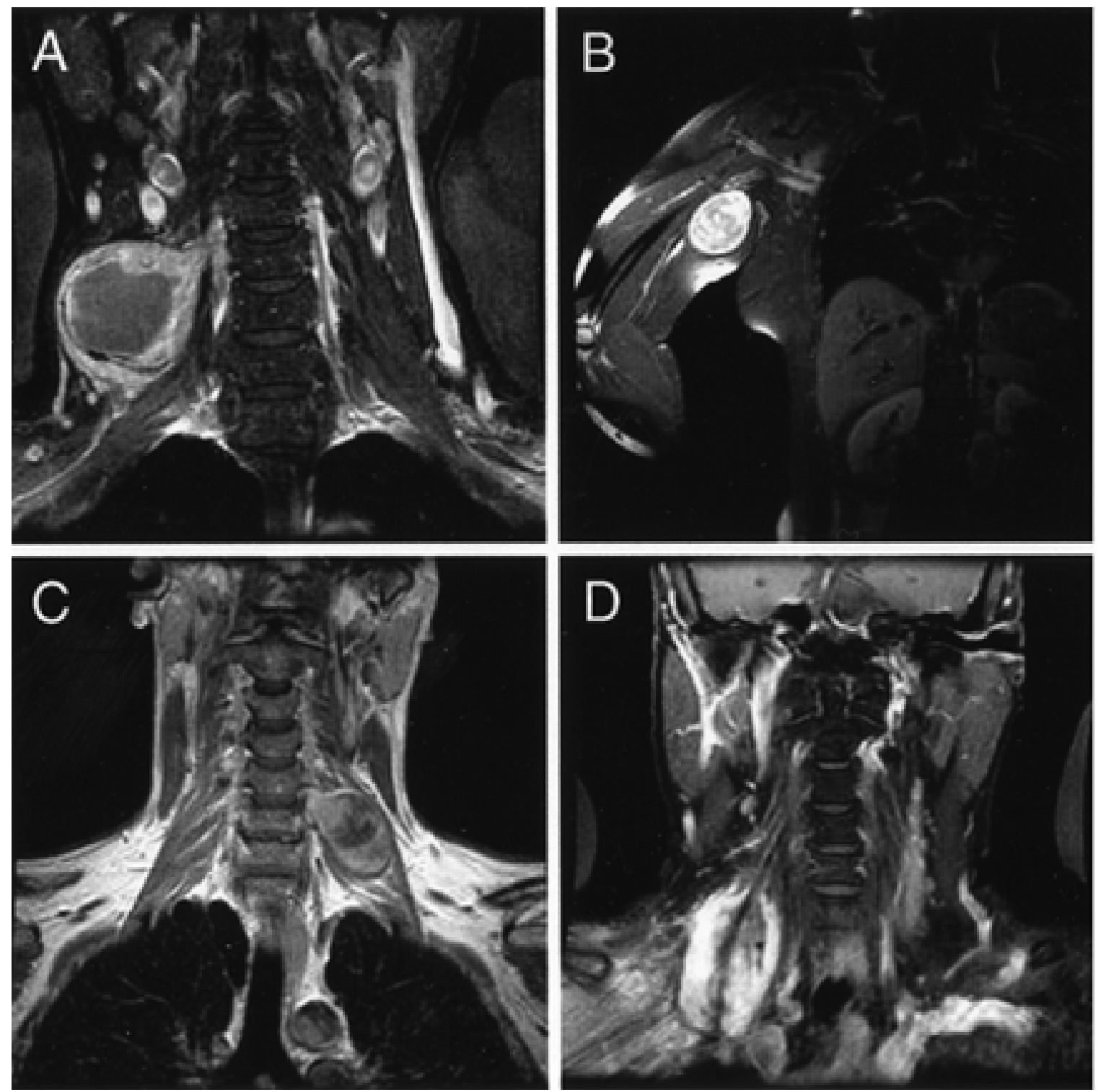

Fig. 1. Representative coronal $\mathrm{T}_{1}$-weighted Gd-enhanced fat-saturation MR images of four different primary brachial plexus tumors. A: Case 23. A cystic schwannoma. A $5.2 \times 4.3 \times 5-\mathrm{cm}$ cystic mass within the subcutaneous tissues of the neck. A soft-tissue component of the mass extends toward the right C5-6 neural foramen. B: Case 9. A neurofibroma. A $5 \times 6 \times 4.8-\mathrm{cm}$ enhancing lesion in the right axillary region. C: Case 15 . An MPNST. A $5.2 \times 3.2 \times 2.9-\mathrm{cm}$ heterogeneous mass arising from the C-6 nerve root with associated widening of the C5-6 left neural foramen. D: Case 8. A desmoid tumor. A $4.8 \times 6.1 \times 6.6-\mathrm{cm}$ heterogeneous mass immediately posterior to proximal right clavicle.

were more difficult to resect completely. Final pathological diagnosis after examination of biopsy specimen or resection together with the clinical course can guide further therapy.

\section{References}

1. Artico M, Cervoni L, Wierzbicki V, et al: Benign neural sheath tumours of major nerves: characteristics in 119 surgical cases. Acta Neurochir 139:1108-1116, 1997

2. Awasthi D, Kline DG, Beckman EN: Neuromuscular hamartoma (benign "triton" tumor) of the brachial plexus. Case report. J Neurosurg 75:795-797, 1991

3. Brasfield RD, Das Gupta TK: Von Recklinghausen's disease: a clinicopathological study. Ann Surg 175:86-104, 1972
4. Burger PC, Scheithauer BW, Vogel FS: Surgical Pathology of the Nervous System and Its Coverings, ed 4. New York: Churchill Livingstone, 2002

5. Cerofolini E, Landi A, DeSantis G, et al: MR of benign peripheral nerve sheath tumors. J Comput Assist Tomogr 15: 593-597, 1991

6. Chui M: Fibromatosis of the brachial plexus and shoulder girdle. Can Assoc Radiol J 40:28-31, 1989

7. Cutler EC, Gross RE: Neurofibroma and neurofibrosarcoma of peripheral nerves unassociated with Recklinghausen's disease: a report of twenty-five cases. Arch Surg 33:733-779, 1936

8. Dart LH Jr, MacCarty CS, Love JG, et al: Neoplasms of the brachial plexus. Minn Med 53:959-964, 1970

9. Das Gupta TK: Tumors of the peripheral nerves. Clin Neurosurg 25:574-590, 1978 
10. Das Gupta TK, Brasfield RD, Strong EW, et al: Benign solitary schwannomas (neurilemmomas). Cancer 24:355-366, 1969

11. Donner TR, Voorhies RM, Kline DG: Neural sheath tumors of major nerves. J Neurosurg 81:362-373, 1994

12. Drake CG: Diagnosis and treatment of lesions of the brachial plexus and adjacent structures. Clin Neurosurg 11:110-127, 1964

13. Ducatman BS, Scheithauer BW: Postirradiation neurofibrosarcoma. Cancer 51:1028-1033, 1983

14. Ducatman BS, Scheithauer BW, Piepgras DG, et al: Malignant peripheral nerve sheath tumors. A clinicopathologic study of 120 cases. Cancer 57:2006-2021, 1986

15. Ellison D, Love S: Neuropathology: A Reference Text of CNS Pathology. London: Mosby, 2000

16. Fenzi F, Moretto G, Zamboni G, et al: Brain metastases from post-radiation malignant peripheral nerve sheath tumor. Ital J Neurol Sci 16:495-498, 1995

17. Filler AG, Howe FA, Hayes CE, et al: Magnetic resonance neurography. Lancet 341:659-661, 1993

18. Filler AG, Kliot M, Howe FA, et al: Application of magnetic resonance neurography in the evaluation of patients with peripheral nerve pathology. J Neurosurg 85:299-309, 1996

19. Foley KM, Woodruff JM, Ellis FT, et al: Radiation-induced malignant and atypical peripheral nerve sheath tumors. Ann Neurol 7:311-318, 1980

20. Ganju A, Roosen N, Kline DG, et al: Outcomes in a consecutive series of 111 surgically treated plexal tumors: a review of the experience at the Louisiana State University Health Sciences Center. J Neurosurg 95:51-60, 2001

21. Godwin JT: Encapsulated neurilemmoma (schwannoma) of the brachial plexus: report of eleven cases. Cancer 5:708-720, 1952

22. Grant GA, Britz GW, Goodkin R, et al: Magnetic resonance imaging for peripheral nerve disorders, in Winn HR (ed): Youmans Neurological Surgery, ed 5. Philadelphia: WB Saunders, 2004, pp 3873-3888

23. Hawkes CH, Jefferson JM, Jones EL, et al: Hypertrophic mononeuropathy. J Neurol Neurosurg Psychiatry 37:76-81, 1974
24. Hosoi K: Multiple neurofibromatosis (von Recklinghausen's disease) with special reference to malignant transformation. Arch Surg 22:258-281, 1931

25. Kim DH, Cho YJ, Tiel RL, et al: Outcomes of surgery in 1019 brachial plexus lesions treated at Louisiana State University Health Sciences Center. J Neurosurg 98:1005-1016, 2003

26. Kline DG, Hudson AR, Tiel R, et al: Management of peripheral nerve tumors, in Winn HR (ed): Youmans Neurological Surgery, ed 5. Philadelphia: WB Saunders, 2004, pp 3941-3957

27. Lederman RJ, Wilbourn AJ: Brachial plexopathy: recurrent cancer or radiation? Neurology 34:1331-1335, 1984

28. Lewis D, Hart D: Tumors of peripheral nerves. Ann Surg 92: 961-983, 1930

29. Lusk MD, Kline DG, Garcia CA: Tumors of the brachial plexus. Neurosurgery 21:439-453, 1987

30. Newbould MJ, Wilkinson N, Mene A: Post-radiation malignant peripheral nerve sheath tumor: a report of two cases. Histopathology 17:263-265, 1990

31. Richardson RR, Siqueira EB, Oi S, et al: Neurogenic tumors of the brachial plexus: report of two cases. Neurosurgery 4: 66-70, 1979

32. Simpson DA, Fowler M: Two cases of localized hypertrophic neurofibrosis. J Neurol Neurosurg Psychiatry 29:80-84, 1966

33. Snyder M, Cancilla PA, Batzdorf U: Hypertrophic neuropathy simulating a neoplasm of the brachial plexus. Surg Neurol 7: 131-134, 1977

34. Vieta JO, Pack GT: Malignant neurilemmomas of peripheral nerves. Am J Surg 82:416-431, 1951

35. Woodhall B: Peripheral nerve tumors. Surg Clin North Am 99:1167-1172, 1954

Manuscript received March 15, 2004.

Accepted in final form April 2, 2004.

Address reprint requests to: Nicholas M. Barbaro, M.D., Department of Neurological Surgery, M779 Moffitt Hospital, Box 0112, University of California, San Francisco, San Francisco, California 94143-0112. email: barbaron@ neurosurg.ucsf.edu. 